\title{
Removal of Fluoride from Aqueous Solution Using Biomass-Based Adsorbents: A Review
}

\author{
Ram Lochan Aryal', Bhoj Raj Poudel', Surendra K Gautam², Hari Paudyal', \\ Megh Raj Pokhrel ${ }^{1}$, Kedar Nath Ghimire ${ }^{1^{*}}$ \\ ${ }^{1}$ Central Department of Chemistry, Tribhuvan University, Kirtipur, Kathmandu, Nepal \\ ${ }^{2}$ Department of Chemistry, Tri-Chandra Multiple Campus, Tribhuvan University, Kathmandu, Nepal \\ *Corresponding E- mail: knghimire@gmail.com \\ (Received: Sept. 30, 2019; Revised: Dec. 23, 2019 \& Accepted: Dec. 24, 2019)
}

\begin{abstract}
Various separation techniques have been successful for the removal of fluoride from aqueous solution. In this review, an extensive list of various biomass-based adsorbents from literature has been explored and their adsorption capacities under different conditions for the removal of fluoride available in the literature to date are presented. Several adsorbents have shown good adsorption capacities, however, modified biomass had shown excellent adsorption capacities compared to commercial materials. This paper reviews the fluoride uptake capacities of biomass materials and their modified forms as adsorbents against different experimental limits.
\end{abstract}

Keywords: Fluoride removal, aqueous solution, adsorption, treatment techniques

\section{Introduction}

In recent years, fluoride and fluorosis are globally common issues. Many developing countries have been facing problems with fluorosis. Due to natural and anthropogenic activities, the ground water becomes infected by fluorides [1,2]. Fluorine is one such pollutant that threatens living organisms especially humans [3]. Fluoride in drinking water has both merits and demerits to human health. Fluorides in trace amounts are essential for living beings for improvement of bone and dental enamel but higher concentration than $1.5 \mathrm{mg} / \mathrm{L}$ causes skeletal and dental fluorosis $[4,5]$. Industries such as glass and ceramic production, electroplating, brick and ironworks, semiconductor manufacturer and aluminum smelters produce fluoride contaminants that are discharged into water resources [6,7]. The effluents of these industries have higher fluoride concentration than natural waters, ranging from ten to thousands of $\mathrm{mg} / \mathrm{L}$ [8]. According to the World Health Organization guidelines (WHO), the fluoride concentration in drinking water should not exceed $1.5 \mathrm{mg} / \mathrm{L}$ [9]. According to the Environmental Protection Agency (EPA) the maximum contaminant level of fluoride ions in drinking water is $4.0 \mathrm{ppm}$ [10-12]. Excess fluoride is toxic but limited fluoride is necessary for calcification of dental enamel and bone formation. Excess intake of fluoride would lead to various diseases such as osteoporosis, arthritis, brittle bones, cancer, infertility in women, male sterility, brain damage, Alzheimer's syndrome, thyroid disorder and even death in severe cases $[13,14]$. About $40 \%$ of ingested fluoride is absorbed in the stomach as HF in aqueous solution. Prolonged and excessive intake of fluoride may result in serious health problems, fluorosis, which is characterized by mottling of teeth in mild cases and even the softening of bones and neurological damage in extreme cases [15]. It has been reported by several research groups that fluoride can interfere with DNA synthesis, carbohydrates, lipids, proteins, vitamins and mineral metabolism $[16,17]$. Besides, on short exposure, a high dose of fluoride affects kidney in both humans and animals [18]. Due to the toxic effects of fluoride on human health, tremendous research and development efforts are being put all over the developing countries for the removal of excess fluoride from drinking water. The removal of fluoride from aqueous solution is of prime concern. The methods for the removal of fluorides include chemical precipitation, ion exchange, membrane filtration, coagulation, electrochemical 
treatments, and adsorption using activated carbon, carbon nanotubes, activated alumina and other natural and synthetic materials [19-24]. Most of these methods have high operational and maintenance costs, low fluoride removal capacities, lack of selectivity for fluoride, low selectivity in presence of other competing ions, generation of large volumes of sludge and complicated procedures in the treatment process. The widely used adsorption methods are activated carbon (AC), activated alumina and other synthetic materials. These techniques cannot work effectively due to the short service life of adsorbent, blockage problem, more cost, and sensitivity to the $\mathrm{pH}$ of the solution [25]. However, the adsorption method has been reported as one of the most effective, economical and eco-friendly of the various defluoridation techniques [26-30].

The biosorption process using biomass waste is an eco-friendly and easy method. It is the promising alternative adsorbent over the conventional adsorbents in the adsorption process.

Table 1: The maximum Fluoride adsorption capacity of various raw adsorbents

\begin{tabular}{|l|l|l|}
\hline Adsorbents & $\begin{array}{l}\text { Adsorption capacity } \\
\mathbf{Q}_{\max }(\mathbf{m g} / \mathbf{g})\end{array}$ & References \\
\hline Citrus limonium leaf & 1.4 & {$[37]$} \\
\hline Sweet lemon peel & 0.744 & {$[38]$} \\
\hline Citrus limetta peel & 1.915 & {$[39]$} \\
\hline Ultrafine Tea powder & 1.26 & {$[40]$} \\
\hline Sandalwood leaf powder & 4.66 & {$[41]$} \\
\hline Banana peel & 8.15 & {$[42]$} \\
\hline Neem leaf powder & 4.70 & {$[43]$} \\
\hline Tamarind fruit shell & 1.53 & {$[44]$} \\
\hline Pipal leaves & 0.80 & {$[45]$} \\
\hline Chitosan & 1.39 & {$[46]$} \\
\hline & & \\
\hline
\end{tabular}

The improved selectivity and sorption capacities of low-cost adsorbents derived from waste bio-mass loaded with metal ions have drawn the attention of many researchers in this field. There is an increasing trend of using biomass-based fluoride adsorbents, very few studies show that raw biomass has the ability of the adsorption of fluorides. But raw biomass can show very low adsorption capacity as compared to the commercial anion exchangers. The adsorption capacities of fluoride by some raw biomass and various commercial adsorbents are shown in Table 1 and Table 2 respectively.
Table 2: The maximum fluoride adsorption capacity of various commercial adsorbents

\begin{tabular}{|l|l|l|}
\hline Adsorbents & $\begin{array}{l}\text { Adsorption Capacity } \\
(\mathbf{m g} / \mathbf{g})\end{array}$ & References \\
\hline La- loaded 200CT resin & 25.46 & {$[46]$} \\
\hline Commercial READF resin & 39.9 & {$[47]$} \\
\hline READF-(PG) & 41.04 & {$[47]$} \\
\hline READF-(HG) & 44.65 & {$[47]$} \\
\hline Amberlite 200 CT & 9.5 & {$[47]$} \\
\hline Hydroxyapatite & 28.57 & {$[48]$} \\
\hline Hardened alumina cement (ALC) & 34.36 & {$[49]$} \\
\hline
\end{tabular}

The low fluoride removal efficiency of raw biomass adsorbent compared to commercial adsorbents (as shown in Table 1 and Table 2) can be described due to the presence of negatively charged functional groups like amino, carboxyl, alcohols and esterson the surface of lignocellulosic materials of bio-mass, while positively charged functional group is limited[31-36].

Table 3: The maximum fluoride adsorption capacity of various agricultural waste adsorbents

\begin{tabular}{|l|l|l|l|}
\hline Adsorbents & Modifying agent & $\begin{array}{l}\text { Adsorption } \\
\text { Capacity (mg/g ) }\end{array}$ & References \\
\hline Seaweed(M - CSW) & $\begin{array}{l}\mathrm{Zr}(\mathrm{IV})-\mathrm{CSW} \\
\mathrm{La}(\mathrm{III})-\mathrm{CSW}\end{array}$ & $\begin{array}{l}18.05 \\
11.02\end{array}$ & {$[20]$} \\
\hline Tea powder & $\mathrm{UTP}-\mathrm{Zr}$ & 12.43 & {$[40]$} \\
\hline Orange waste gel & $\begin{array}{l}\text { Saponification by } \\
\text { loading Zr (IV) }\end{array}$ & 22.8 & {$[47]$} \\
\hline Azollafiliculoides & $\mathrm{HCl}$ & 11.2 & {$[50]$} \\
\hline Orange waste & $\begin{array}{l}\text { Conc. Sulphuric } \\
\text { acid, Zr(IV) }\end{array}$ & 13.49 & {$[51]$} \\
\hline Porous corn starch & $\mathrm{PS}-\mathrm{Zr}$ & 25.41 & {$[52]$} \\
\hline Rice husk & $\mathrm{Al}(\mathrm{OH})_{3}$ Coated & 14.82 & {$[53]$} \\
\hline Rice straw & $\mathrm{KMnO}{ }_{4}$ Modified & 15.77 & {$[54]$} \\
\hline Cotton cellulose & Iron loaded & 18.43 & {$[55]$} \\
\hline Orange waste & La-SOJR & 20.33 & {$[56]$} \\
\hline Orange waste & Sc - SOJR & 11.4 & {$[56]$} \\
\hline
\end{tabular}

Due to the lack of anion binding sites on the polymeric backbone, raw biomass-based adsorbents are found to be less effective in the removal of fluoride. In addition, the polymeric organic compounds (cellulose, lignocellulose and lignin) can leach into the aqueous solution so raw biomass-based adsorbent retards the adsorption capacity of fluoride anion. Thus, in order to increase the adsorption capacity of raw biomass, it is modified depending on the nature of pollutants, which is depicted in Table 3 . The adsorption capacity of modified metal loaded adsorbents is found to be excellent due to its high binding sites, selectivity towards fluoride, large surface area and chemical stability. 


\section{Mechanism of fluoride adsorption}

Bio waste consists of cellulose, hemicellulose, pectin, lignin, and polyoses. Pectin contains carboxyl groups as well as its methyl ester groups. The methyl ester portion of pectin can be converted into a carboxyl group by saponification reaction using $\mathrm{Ca}(\mathrm{OH})_{2}$ or $\mathrm{NaOH}$ ions that enhances the ligand exchange mechanism with fluoride ions. The equilibrium $\mathrm{pH}$ of the solution is found to be increased after the adsorption of fluoride indicating that hydroxyl ions are released during adsorption, which further supports the mechanism mentioned below [56].

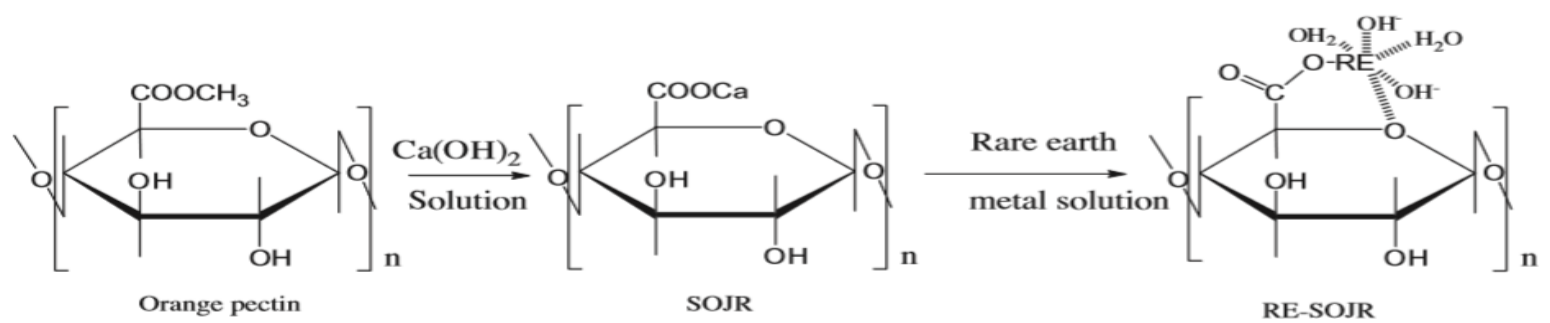

Figure 1: Adapted mechanism of saponification followed by metal ion loading

Thus, obtained saponified waste is further treated with rare earth metal ions. The carboxyl group and oxygen atom of the pyranose ring of pectic acid in the bio-waste form a stable five-membered chelate with the loaded metal ion. Due to hydroxyl ions as well as water molecules present in the coordination sphere of metal ions, it exhibits the ligand exchange mechanism with fluoride ions. Due to the steric hindrance of pectic acid, it is difficult to neutralize all the positive charges of the loaded metal ions with carboxyl groups. So, one or two positive charges of the loaded metal ion can be neutralized by carboxyl groups while other positive charges are neutralized by hydroxyl ions in the solution. The increase in the oxidation state of loaded metal ions increases the number of hydroxyl ions on the coordination spheres of the loaded metal

\section{Factors affecting adsorption}

\section{Effect of pH}

The $\mathrm{pH}$ of an aqueous solution is an important parameter for the adsorption at a solution adsorbent interface. The adsorption of fluoride increases with increasing $\mathrm{pH}$ and it is in the $\mathrm{pH}$ range of 2-4, because of the presence of more protonated sites in the ion exchange with $\mathrm{F}^{-}$, then decreased with further increase in $\mathrm{pH}$. The low adsorption at low $\mathrm{pH}(\mathrm{pH}<2)$ may be due to the formation of weakly ionizable hydrofluoric acid ( $\mathrm{pK}_{\mathrm{a}}$ of $\mathrm{HF}=3.2$ ) or more than $95 \%$ of fluoride remains in the non-ionic form which is difficult to be adsorbed onto the anion exchange site of the adsorbent. The maximum fluoride adsorption was found to occur at $\mathrm{pH} 2-4$. The decrease in fluoride adsorption at $\mathrm{pH}$ above 5 is due to the competition

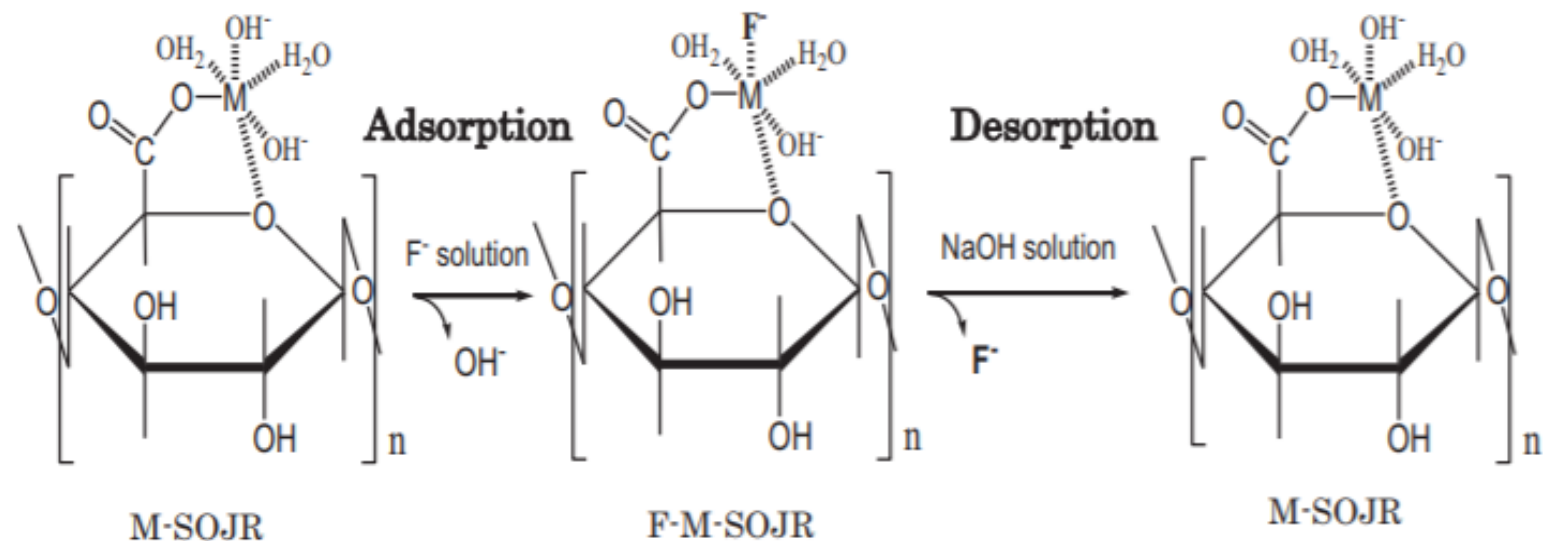

Figure 2: Adapted Mechanism on the adsorption and desorption of fluoride ion [56] 
of hydroxide ions for the adsorption sites because hydroxide ion concentration increases with the rise of $\mathrm{pH}$ of the solution $[20,56,57]$.

\section{Effect of initial fluoride concentration and adsorbent dose}

The fluoride adsorption was found to be affected by both the adsorbent dose and the initial fluoride concentration. It was found that for a fixed fluoride concentration, the percentage of adsorption gradually increases with increasing adsorbent dose from $1.0 \mathrm{mg} / \mathrm{g}$ to $5.0 \mathrm{mg} / \mathrm{g}$ at $303 \mathrm{~K}$. It might be due to the increased surface area and availability of more adsorption sites for fluoride adsorption. But for a constant dose, total available adsorption sites were limited so due to limited available adsorption sites, at higher concentrations of fluoride solution, there would be extreme competition among fluoride ions for the adsorption sites resulting in the decrease or constancy in adsorption [41]. Dehghani et al. [57] studied that fluoride adsorption increases with increasing adsorbent dose due to a greater extent of adsorption sites and more surface area.

\section{Effect of contact time and kinetic study}

The contact time of fluoride and adsorbent during adsorption is important in determining the kinetics of the process. The adsorption of fluoride depends on the contact time of the adsorbent and solution. Rapid uptake of fluoride and establishment of equilibrium in a short period of time denotes the efficiency of the adsorbents. In physical adsorption, most of the fluoride is adsorbed within a short interval of contact time. However, strong chemical bonding of the fluoride with adsorbents needs a longer contact time to reach equilibrium. In the beginning, the adsorption of fluoride increases rapidly with an increase in contact time then slows down and reaches equilibrium [57]. Khound et al. [41] studied the adsorption of fluoride with Sandalwood leaf powder (SLP) and the amount of adsorption increased with time upto $120 \mathrm{~min}$. The rapid removal of fluoride at initial stages might be due to the vacant adsorption sites and it can adsorb more fluoride ions from the solution. The time-dependent adsorption data have been analyzed using three kinetic models, pseudo-first-order, pseudo-second-order and intraparticle diffusion model.

\section{Adsorption isotherms}

The adsorption isotherm determines how the fluoride molecules distribute between the liquid and solid phase during the adsorption process at an equilibrium state. Adsorption isotherm provides information about the effectiveness of the biomass for the removal of fluoride from contaminated water. The adsorption data were analyzed using Langmuir, Freundlich, Temkin, Redlich-Peterson and Sips isotherm [58]. Cai et al. [40] studied the Zr-loaded tea powder which is best fitted with the Langmuir isotherm model based on monolayer adsorption of adsorbate onto the adsorbent surface with the limited number of binding sites. Abu Bakar et al. [58] studied modified Palm Kernel Shell which is fitted with Freundlich, Redlich-Peterson and Sips isotherm.

\section{Thermodynamic study}

The thermodynamic feasibility and the spontaneity can be predicted by observing the effect of change of temperature upon the adsorption process and hence evaluating thermodynamic parameters; Gibb's free energy of adsorption $\left(\Delta \mathrm{G}^{0}\right)$, enthalpy of adsorption $\left(\Delta \mathrm{H}^{0}\right)$ \& entropy of adsorption $\left(\Delta \mathrm{S}^{0}\right)$. An adsorption process is generally considered as physical if $\Delta \mathrm{H}^{0}<$ $84 \mathrm{KJ} / \mathrm{mol}$ and the chemical if $\Delta \mathrm{H}^{0}$ lies between $84-$ $420 \mathrm{~kJ} / \mathrm{mol}$ [59]. With the rise in temperature, fluoride adsorption increases if adsorption is endothermic and decreases for the exothermic process.

\section{Effect of co-existing anions}

Various anions in the solution can interfere with fluoride removal in the adsorption process. The percentage of fluoride removal decreases in the presence of $\mathrm{PO}^{4--}, \mathrm{SO}^{4--}, \mathrm{NO}^{3-}$ and $\mathrm{Cl}^{-}$anions. The uptake capacity depends on ionic radii. Ionic radii of fluoride, chloride and nitrate ions are $0.133,0.181$ and $0.179 \mathrm{~nm}$ which is quite similar. The ionic radii and surface charge densities of phosphate $(0.238$ $\mathrm{nm})$ and sulphate $(0.230 \mathrm{~nm})$ anions are larger than of fluoride ions and interfere with the adsorption of fluoride at the active site. Sometimes, the addition of competitor anions in water causes an increase in $\mathrm{pH}$. This increases in $\mathrm{pH}$ value results in the decrease of fluoride adsorption [57].

\section{Conclusion}

This review has attempted to cover a wide range of adsorbents and treatment techniques which have been used for the removal of fluoride from aqueous solution. The capacity of treatment techniques and 
their merits and limitations were highlighted. In addition to this, different types of adsorbent and their adsorption capacities were presented. It showed that chemically modified metal loaded biomass for the removal of pollutants has attracted the attention of more researchers. Chemically modified adsorbents enhance the adsorption capacity of fluoride due to a higher number of active binding sites, selective metal ion adsorption, rapid adsorption kinetics, improve structural stability and ion exchange capacity. These adsorbents were found to be efficient for fluoride removal, not only from the industries but also from the living organisms and the surrounding environment. The use of biomass adsorbents may contribute to the sustainability of the environment and water resources. Undoubtedly, biomass adsorbents provide a lot of promising benefits for commercial purposes in the future. More studies should be carried out for lowcost adsorption processes to enhance large scale use of biomass adsorbents. Low-cost adsorbents should be used to minimize cost and maximize heavy metal removal efficiency.

\section{References}

1. N. Sivarajasekar, T. Paramasivan, S. Muthusaravanan, P. Muthukumaran and S. Sivamani, Defluoridation of water using adsorbents - A concise review, Journal of Environment and Biotechnology Research, 2017, 6, 186 - 198.

2. V. Sivasankar, S. Murugesh, S. Raj Kumar and A. Darchen, Cerium dispersed in carbon (CeDC) and its adsorption behaviour: A first example of tailored adsorbent for fluoride removal from drinking water, Chemical Engineering Journal, 2013, 214, 45-54.

3. K. N. Ghimire, Effective removal of fluoride onto metal ions loaded orange waste, Journal of Nepal Chemical Society, 2011, 27, 61-66. (https://doi. org/10.3126/ jncsv27i1.6660).

4. E. J. Reardon and Y. Wang, A limestone reactor for fluoride removal from waste waters, Environmental Science \&Technology, 2000, 34, 3247-3253.

5. P. Koilraj and S. Kannan, Aqueous fluoride removal using $\mathrm{Zn}$-Cr layered double hydroxides and their polymeric composites: Batch and column studies, Chemical Engineering Journal, 2013, 234, 406415.
6. F. Shen, X. Chen, P. Gao, and G. Chen, Electrochemical removal of fluoride ions from industrial waste water, Chemical Engineering Science, 2003, 58, 987-993.

7. D. L. Adhikari, R. L. Aryal, S. Bhattarai, S. K. Gautam and B. R. Poudel, Removal of chromium (VI) from aqueous solution using chemically modified sweet lime (Citrus limetta) peels as adsorbent, Journal Nepal Chemical Society, 2017, 36, 82-95.

8. K. A. Krishnan and A. Haridas, Removal of phosphate from aqueous solutions and sewage using natural and surface modified coir pith, Journal of Hazardous Materials, 2008, 152 (2), 527-535.

9. K. N. Ghimire, K. Inoue, K. Makino and R. P. Dhakal, Adsorptive removal of arsenic and fluoride by using orange juice residue, Electrometallurgy and Environmental Hydrometallurgy, 2003, 2, 1937-1950.

10. S. Ayoob, A. K. Gupta and V.T. Bhat, A conceptual overview on sustainable technologies for the defluoridation of drinking water, Critical Reviews in Environmental Science and Technology, 2008, 38, 401-470.

11. N. Kawashima, R. Wadachi, H. Suda, T. Yeng and P. Parashes, Root canal medicaments, International Dental Journal, 2009, 59, 5-11.

12. J M. Kauffman, Water fluoridation: A review of recent research and actions, Journal of American Physicians and Surgeons, 2005, 10(2), 38.

13. R. Lavecchia, F. Medici, L. Piga, G. Rinaldi and A. Zuorro, Fluoride removal from water by adsorption on a high alumina content bauxite, Chemical Engineering Transactions, 2012, 26, 225-230.

14. K. Abu Zeid and L. Elhatow, Impact of fluoride content in drinking water, In Arab Water Healthy Conference Egypt: Cairo, 2007.

15. R. C. Meenakshi Maheshwari, Fluoride in drinking water and its removal, Journal of Hazardous Materials, 2006, 137, 456-463.

16. S. K. Jha, R. K. Singh, T. Damodaran, V. K. Mishra, D. K. Sharma, D. Rai, Fluoride in groundwater: toxicological exposure and remedies, Journal of 
Toxicology and Environmental Health, Part B, 2013, 16(1), 52-66.

17.X. Fan, D. J. Parker and M. D. Smith, Adsorption kinetics of fluoride on low cost materials, Water Resources, 2003, 37, 4929-4937.

18. Y. Zhou, C. Yu and Y. Shan, Adsorption of fluoride from aqueous solution on $\mathrm{La}^{3+}$ impregnated cross-linked gelatin, Separation and purification Technology, 2004, 36, 89-94.

19.M. Islam and R.K. Patel, Thermal activation of basic oxygen furnace slag and evaluation of its fluoride removal efficiency, Chemical Engineering Journal, 2011, 169, 68-77.

20.H. Paudyal, B. Pangeni, K. Inoue, H. Kawakita, K. Ohto, K. N. Ghimire and S. Alam, Preparation of novel alginate based anion exchanger from Ulva japonica and its application for the removal of trace concentrations of fluoride from water, Bioresource Technology, 2013, 148, 221-227.

21. N. Meunier, J. F. Blais and R. D. Tyagi, Selection of a natural sorbent to remove toxic metal from acidic leachate produced during soil decontamination, Hydrometallurgy, 2002, 67, 19-30.

22. V. K. Gupta and T. A. Saleh, Sorption of pollutants by porous carbon, carbon nanotubes and fullereneAn overview, Environmental Science \& Pollution Research, 2013, 20, 2828-2843.

23. A. Shrestha, B. R. Poudel, M. Silwal and M. R. Pokhrel, Adsorptive removal of phosphate onto Iron loaded Litchi chinesis, Journal of Institute of Science and Technology, 2018, 23, 81-87.

24. P. R. Bhatt, R. L. Aryal, B. R. Poudel, S. Bhattarai and S. K. Gautam, Adsorptive removal of Cr (VI) from aqueous solution onto charred sugarcane bagasse, Journal Nepal Chemical Society, 2018, 39,62-69.

25. M. A. Barakat. New trends in removing heavy metals from industrial waste water, Arabian Journal of Chemistry, 2011, 4(4), 361-77.

26.Z. Song, C. Z. Williams and R. G. Edyvean, Treatment of tannery waste water by chemical coagulation, Desalination, 2004, 164(3), 249-59.

27.D. Rajkumar and K. Palanivelu, Electrochemical treatment of industrial Wastewater, Journal of
Hazardous Materials, 2004, 113, 123-129.

28.C. Namasivayam and D. Kavitha, Removal of Congo red from water by adsorption onto activated carbon prepared from coir pith, an agricultural solid waste, Dyes and Pigments, 2002, 54, 47-58.

29. V. K. Gupta, T. A. Saleh, Sorption of pollutants by porous carbon, carbon nanotubes and fullerene-an overview, Environmental Science and Pollution Research, 2013, 20(5), 2828-2843.

30.I. Ali, New generation adsorbents for water treatment, Chemical Reviews, 2012, 112, 50735091 .

31. K. Biswas, K. Gupta and U. C. Ghosh, Adsorption of fluoride by hydrous iron(III)-Tin(IV) bimetal mixed oxide from the aqueous solutions, Chemical Engineering Journal, 2009, 149, 196-206.

32.F. Fu and Q. Wang. Removal of heavy metal ions from wastewaters: a review, Journal of Environmental Management, 2011, 92(3), 407-18.

33. S. Kagne, S. Jagtap, P. Ddhawade, S. P. Kamble, S. Devotta and S. S. Rayalu, Hydrated cement: A promising adsorbent for the removal of fluoride from aqueous solution, Journal of Hazardous Materials, 2008, 154, 88-95.

34. Y. Deng, D. K. Nordstrom and R. B. McCleskey, Fluoride geochemistry of thermal waters in Yellowstone National Park: I. Aqueous fluoride speciation, Geochimica et Cosmochimica Acta, 2011, 75, 4476-4489.

35. M. R. Pokhrel, B. R. Poudel, R. L. Aryal, H. Paudyal and K. N. Ghimire, Removal and recovery of phosphate from water and wastewater using metal-loaded agricultural waste-based adsorbents: a review, Journal of Institute of Science and Technology, 2019, 24(1), 77-89.

36. S. Karki, R. L. Aryal, S. R. Bhattrai, S. K. Gautam and B. R. Poudel, Adsorptive removal of Arsenic (III) from aqueous solution using chemically modified sweet lime (Citrus limetta) peels, Journal of Nepal Chemical Society, 2017, 37,11-19.

37. V. Tomar, S. Prasad and D. Kumar, Adsorptive removal of fluoride from aqueous media using Citrus limonum (lemon) leaf, Microchemical Journal, 2014, 112, 97-103. 
38. A. Mohammad and C. B. Majumder, Removal of fluoride from synthetic waste water by using bioadsorbents, International Journal of Research in Engineering and Technology, 2014, 3, 776-784.

39.T. Singhand and C. B. Majumder, Kinetics for removal of fluoride from aqueous solution through adsorption from mousambi peel, ground nut shell and neem leaves, International Journal of Science Engineering Technology, 2015, 3(4), 879-883.

40.H. Cai, L. Xu, G. Chen, C. Peng, F. Ke, Z. Liu, D. Li, Z. Zhang and X. Wan, Removal of fluoride from drinking water using modified ultrafine tea powder processed using a ball-mill, Applied Surface Science, 2016, 375, 74-84.

41.N. J. Khound and R. K. Bharali, Biosorption of fluoride from aqueous medium by Indian sandalwood (Santalum Album) leaf powder, Journal of Environmental Chemical Engineering, 2018, 6, 1726-1735.

42. N. K Mondal and A. Roy, Potentiality of a fruit peel (banana peel) toward abatement of fluoride from synthetic and underground water samples collected from fluoride affected villages of Birbhum district, Applied Water Science, 2018, 8(3), 90.

43. R. K. Bharali and K. G. Bhattacharyya, Biosorption of fluoride on Neem (Azadirachta indica) leaf powder, Journal of Environmental Chemical Engineering, 2015, 3, 662-669.

44.V. Ramanjaneyulu, M. Jaipal, N. Yasovardhan and S. Sharada, Kinetic studies on removal of fluoride from drinking water by using tamarind shell and pipal leaf powder, International Journal of Emerging Trends in Engineering and Development, 2013, 5, 146-155.

45. M. A. M. Sahli, S. Annouar, M. Tahaikt, M. Mountadar, A. Soufiane and A. Elmidaoui, Fluoride removal for underground brackish water by adsorption on the natural chitosan and by electrodialysis, Desalination, 2007, 21, 37-45.

46. L. Fang, K. N. Ghimire, M. Kuriyama and K. Inoue. Removal of fluoride using some lanthanum (III) loaded adsorbents with different functional groups and polymer matrices, Journal of Chemical Technology and Biotechnology, 2003, 78, 10381047.
47. H. Paudyal, B. Pangeni, K. Inoue, M. Matsueda, R. Suzuki, H. Kawakita, K. Ohto, B. K. Biswas and S. Alam, Adsorption behaviour of fluoride ions on Zirconium (IV)-loaded orange waste gel from aqueous solution, Separation Science and Technology, 2012, 47, 96-103.

48. A. Samant, B. Nayak and P. K. Mishra, Kinetics and mechanistic interpretation of fluoride removal by nanocrystalline hydroxyapatite derived from Limacine artica shells, Journal of Environmental Chemical Engineering, 2017, 5, 5429-5438.

49. S. Ayoob and A. K. Gupta, Insights into isotherm making in the sorptive removal of fluoride from drinking water, Journal of Hazardous Materials, 2008, 152, 976 - 958.

50. M. A. Zazouli, A. H. Mahvi, S. Dobaradaran, M. Barafrashtehpour, Y. Mahdavi and D. Balarak, Adsorption of fluoride from aqueous solution by modified Azolla filiculoides, Adsorption, 2014, 47(4), 349-358.

51.H. Paudyal, B. Pangeni, K. Inoue, H. Harada, H. Kawakita, K. Ohto and S. Alam, Adsorptive removal of trace concentration of fluoride using orange waste treated using concentrated sulfuric acid, International Journal of Materials Science and Applications, 2017, 6, 212-222.

52. L. Xu, G. Chen, C. Peng, H. Qiao, F. Ke, R. Hou and X. Wan, Adsorptive removal of fluoride from drinking water using porous starch loaded with common metal ions, Carbohydrate Polymers, 2017, 160, 82-89.

53. V. Ganvirand K. Das, Removal of fluoride from drinking water using aluminum hydroxide coated rice husk ash, Journal of hazardous materials, 2012, 185(2-3), 1287-1294.

54. A. A. M. Daifullah, S. M. Yakout and S. A. Elreefy, Adsorption of fluoride in aqueous solutions using $\mathrm{KMnO}_{4}$-modified activated carbon derived from steam pyrolysis of rice straw, Journal of Hazardous Materials, 2007, 147(1-2), 633-643.

55. Y. Zhao, X. Li, L. Liu and F. Chen, Fluoride removal by $\mathrm{Fe}(\mathrm{III})$-loaded ligand exchange cotton cellulose adsorbent from drinking water, Carbohydrate Polymers, 2008, 72(1), 144-150. 
56. H. Paudyal, B. Pangeni, K. Inoue, H. Kawakita, K. Ohto, H. Harada and S. Alam, Adsorptive removal of fluoride from aqueous solution using orange waste loaded with multi-valent metal ions, Journal of Hazardous Materials, 2011, 192, 676682.

57. M. H. Dehghani, M. Farhang, M. Alimohammadi, M. Afsharnia and G. Mckay, Adsorptive removal of fluoride from water by activated carbon derived from $\mathrm{CaCl}_{2}$-modified Crocus sativus leaves: Equilibrium adsorption isotherms, optimization, and influence of anions, Chemical Engineering Communications, 2018, 205, 955-965.
58. A. H. B. A. Bakar, Y. S. Koay, Y. C. Ching, L. C. Abdullah, T. S. Y. Choong, M. Alkhatib, M. N. Mobarekeh and N. A. M. Zahri, Removal of fluoride using quaternized palm kernel shell as adsorbents: equilibrium isotherms and kinetics studies, BioResources, 2016, 11, 4485-4511.

59. M. Horsfall Jnr, and A. I. Spiff, Effects of temperature on the sorption of $\mathrm{Pb}^{2+}$ and $\mathrm{Cd}^{2+}$ from aqueous solution by caladium bicolor (Wild cocoyam) biomass, Electronic Journal of Biotechnology, 2005, 8, 43-50. 